\title{
Resolução de situações-problemas do campo conceitual multiplicativo: o cálculo relacional e o numérico
}

\author{
Solving problem situations of the multiplicative conceptual field: the relational and \\ numeric calculus
}

\author{
Elisângela Bastos de Mélo Espindola \\ ebmespindola@gmail.com
}

Isabela Fernanda Melo de Moura fernandabuba@gmail.com

\begin{abstract}
Resumo
Apresentamos os resultados de um estudo com o objetivo de identificar as dificuldades dos alunos do $6^{\circ}$ ano do Ensino Fundamental no cálculo relacional e numérico na resolução de situações-problema do campo conceitual multiplicativo. Este estudo foi baseado na Teoria dos Campos Conceituais de Vergnaud (1990). Dentre os procedimentos metodológicos, 150 alunos de uma escola da rede pública estadual de Recife-PE foram solicitados a responder cinco situações-problemas; sendo duas de relação quaternária (proporção simples) e três de relação terciária (comparação multiplicativa e produto de medidas). Os resultados indicam um maior número de acertos na situação-problema do eixo proporção simples (partição). Enquanto as situações-problemas do eixo comparação multiplicativa (procura do referente) e a do eixo produto de medidas (combinatória) foram aquelas que os alunos apresentaram maior dificuldade em respondê-las. De modo geral, em todas as situaçõesproblemas, as dificuldades dos alunos foram maiores no cálculo relacional que no cálculo numérico.
\end{abstract}

Palavras-chave: Teoria dos Campos Conceituais; Campo das estruturas multiplicativas; Cálculo relacional; Cálculo numérico; Ensino fundamental.

\begin{abstract}
We introduce the results of a study whose objective wasto identifythe difficulties the students from the sixth grade of Junior High School have about the relational and numeric calculusin solving Problem Situations of the Multiplicative Conceptual field (MCF). This study is based on Vergnaud Theory of Conceptual fields (1990). Among the methodological procedures, a hundred fifty students from Recife's Public school have been required to answer five Problem Situations. Two of Quarternary relation (simple proportion) and three of ternary relation (multiplicative comparison and measure product). The results indicate a great number of scores in Problem situations of the axis Simple proportion, while the Problem situations of the axis Multiplicative comparison (search for the referent) and the axis Measure products (combinatory) have been the ones the students showed more difficulties to answer. In general, the difficulties of the students have been bigger in the relational calculus than in numeric.
\end{abstract}

Key words: Theory of Conceptual Fields; Field of multiplicative structures; Numeric calculus; Junior high school.

\section{Introdução}

Documentos de orientações curriculares oficiais, a exemplo dos Parâmetros Curriculares Nacionais (BRASIL, 1998) e dos Parâmetros Curriculares de Pernambuco (PERNAMBUCO, 2012), à luz da Teoria dos Campos Conceituais, têm sublinhado a importância da apresentação aos alunos nos primeiros anos do Ensino Fundamental de 
diferentes tipos de situações-problemas, dentre outras, referentes ao campo conceitual multiplicativo (ideia de multiplicação comparativa, a noção de proporcionalidade, a contagem de configurações retangulares, a combinação de elementos de diferentes maneiras, partição, busca do número de cotas).

Desta forma, questionamos a aprendizagem dos alunos referente a estes tipos de situações-problemas quando se encontram no $6^{\circ}$ ano do Ensino Fundamental; ou seja, ao terem concluído os anos iniciais do Ensino Fundamental. Para tanto, trilhamos o objetivo de reconhecer as dificuldades dos alunos na resolução de situações-problemas, demonstradas nos seus procedimentos de cálculo relacional e numérico.

Sublinhamos neste estudo, dentre outras aspectos, alguns elementos sobre a compreensão e interpretação dos problemas pelos alunos. A passagem da linguagem natural para a linguagem matemática, no momento da escolha da operação adequada para resolver uma dada situação-problema (cálculo relacional). Assim como os conhecimentos aritméticos em torno das operações, os procedimentos algorítmicos (cálculo numérico).

\section{A Teoria dos Campos Conceituais e o campo conceitual multiplicativo}

A Teoria dos Campos Conceituais considera que um conceito não pode ser reduzido a sua definição se nos interessamos a sua aprendizagem e a seu ensino. Vergnaud (1990) apresenta um conceito como formado como uma trinca de conjuntos indissociáveis $(\boldsymbol{S}, \boldsymbol{I}, \boldsymbol{R})$.

S: conjunto de situações que dão sentido ao conceito. (referência);

I: conjunto dos invariantes sobre os quais repousa a operacionalidade dos esquemas (significado);

$\boldsymbol{R}:$ conjunto das formas linguísticas e não linguísticas que permitem representar simbolicamente o conceito, suas propriedades, as situações e os procedimentos de tratamento (significante) (VERGNAUD, 1990, p. 145).

Nesse sentido, o estudo de um conceito deve considerar ao mesmo tempo: "o plano das situações, o dos invariantes operatórios e o das representações simbólicas. Não há em geral bijeção entre seus significantes e significados, nem entre [esquema] invariante e situações" (FRANCHI, 1999, p. 173).

$\mathrm{Na}$ Teoria dos Campos Conceituais os processos cognitivos e as respostas do sujeito ocorrem em função das situações as quais ele é confrontado. Vergnaud aponta duas ideias principais sobre "situações":

1. A de variedade: existe grande variedade de situação num campo conceitual dado; as variáveis de situação são um meio de construir sistematicamente o conjunto das classes possíveis. 
2. A de historia: os conhecimentos dos alunos são elaborados por situações que eles enfrentaram e dominaram progressivamente, sobretudo para as primeiras situações suscetíveis de dar sentido aos conceitos e procedimentos que se pretende ensinar-lhes (VERGNAUD, 1993, p.12).

De acordo com Franchi (1999, p. 157) "o conhecimento se constitui e se desenvolve no tempo em interação adaptativa do indivíduo com as situações que experiência". Sublinhamos que um conceito não assume sua significação em uma só classe de situações, e uma situação não é analisada por meio de um conceito único. (VERGNAUD, 1993). São as situações que dão sentido aos conceitos matemáticos, mas o sentido não está nas situações em si mesmas.

Sobre os invariantes operatórios (teoremas-em-ação e conceitos-em-ação), Moreira (2002, p.12) explica que estes dirigem o reconhecimento, por parte do indivíduo, dos elementos pertinentes à situação; "são os conhecimentos contidos nos esquemas; são eles que constituem a base, implícita ou explícita, que permite obter a informação pertinente e dela inferir a meta a alcançar e as regras de ação adequadas". Sobre a noção de esquema ele ainda abrange:

- Antecipações da meta a atingir, efeitos esperados e eventuais etapas intermediárias;

- Regras de ação do tipo "se... então..." que permitem gerar sequência das ações do sujeito;

- Inferências (ou raciocínios) que permitem "calcular" as regras e as antecipações a partir das informações e do sistema de invariantes operatórias de que o sujeito dispõe. (VERGNAUD, 1993, p 19).

As operações de pensamento desenvolvidas na resolução de um problema, exprime outro aspecto importante da Teoria dos Campos Conceituais: o papel da linguagem verbal e de outros modos de representação simbólica, no processo de conceitualização do real. As representações linguísticas e não linguísticas que permitem representar simbolicamente o conceito possuem uma função tríplice: representação dos segmentos pertinentes da situação, representação da ação e, representação das relações entre a ação e a situação. (VERGNAUD, 1993, p. 19)

$\mathrm{Na}$ construção de conceitos, a possibilidade de diversas representações simbólicas, condizem ao funcionamento e o desenvolvimento de propriedades e relações na aquisição de conhecimentos matemáticos que podem ser mobilizados na operacionalidade destes. De fato, os significantes (símbolos e sinais) representam significados que são eles menos de ordem cognitiva e psicológica (FRANCHI 1999). 
Convém salientar que embora no conjunto das representações simbólicas, a linguagem e os símbolos matemáticos desempenhem um papel importante na conceitualização e na ação, sem os esquemas e as situações, eles seriam vazios de sentido (VERGNAUD, 1990).

De acordo com Moreira (2002) as situações é que são responsáveis pelo sentido atribuído ao conceito, um conceito torna-se significativo através de uma variedade de situações. Entendemos assim, que quanto mais situações-problemas sejam exploradas maior possibilidade se tem que os alunos desenvolvam a aprendizagem de um conceito de modo mais compreensivo.

Particularmente, quando nos referimos ao campo conceitual multiplicativo, consideramos este como sendo "um conjunto de problemas ou situações, cuja análise e tratamento requerem vários tipos de conceitos, procedimentos e representações simbólicas, os quais se encontram em estreita conexão uns com os outros" (MAGINA; MERLINI; SANTANA, 2013, p. 5982). Campo este, formado por um conjunto de situações que envolvem a divisão e a multiplicação isoladamente ou a combinação dessas operações, bem como, outros conceitos matemáticos.

De acordo com Pessoa e Filho (2006, p.5) Vergnaud descreve três grandes classes de problemas multiplicativos que envolvem relações ternárias e quaternárias: isomorfismo de medidas, produto de medidas e proporções múltiplas. Ao fazerem uma releitura sobre a classificação proposta por Vergnaud sobre os problemas multiplicativos, Magina, Merlini e Santana (2013) classificaram estes como apresentado na figura a seguir:

Figura 1: Síntese do campo conceitual multiplicativo

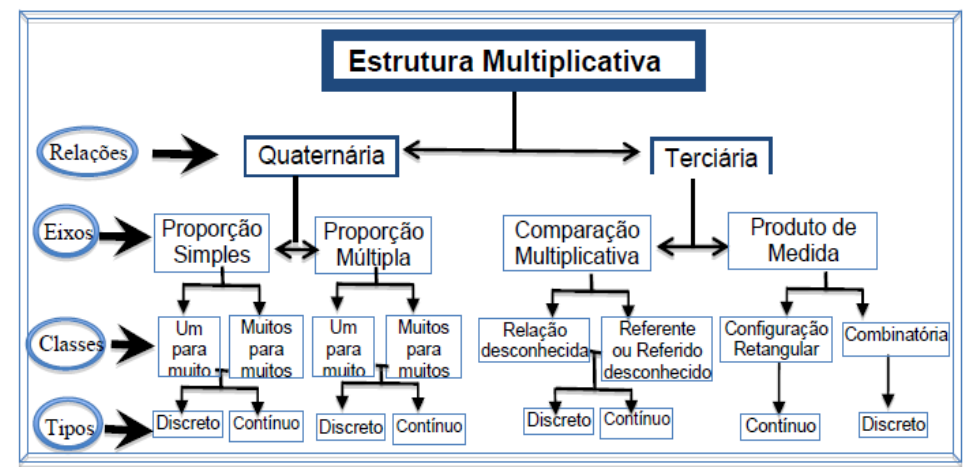

Fonte: Magina; Merlini e Santana (2013, p.5983).

Sobre as relações, elas são quaternárias quando o problema oferece três elementos e se pergunta pelo quarto, já as relações terciárias, apenas dois elementos são enunciados e se pergunta pelo terceiro (MAGINA; MERLINI; SANTANA, 2013). 
As relações quaternárias (Figura 1) são compostas de dois eixos: proporção simples e proporção múltipla. O eixo proporção simples envolve uma relação entre quatro quantidades, sendo duas de um tipo e as outras duas de outro tipo ou, então, uma simples proporção direta entre duas grandezas. O eixo proporção múltipla, refere - se às situações que envolvem uma relação quaternária entre mais de duas variáveis relacionadas duas a duas.

As relações terciárias (Figura 1) são constituídas por dois eixos: comparação multiplicativa (subdividido em relação desconhecida e o referido ou referente desconhecido) e produto de medida (subdividido em configuração retangular a combinatória) levando em consideração dois tipos de quantidades (continua e discreta), exceto para os problemas envolvendo a ideia de combinatória, para os quais não faz sentido pensar na formulação de problemas envolvendo quantidade contínua.

No presente estudo, investigamos as situações-problemas da relação quaternária (eixo proporção simples) e da relação terciária (eixos multiplicação comparativa e combinatória) a partir dos procedimentos de cálculos dos alunos para resolvê-las. .

\section{O cálculo relacional e o cálculo numérico}

Em sua discussão sobre a resolução de problemas matemáticos Queiroz e Lins (2011) coloca que Vergnaud fornece uma teorização que nos permite analisar a natureza do erro do aluno. Ou seja, o entendimento do que o aluno pensa e faz para chegar à resposta do problema. Pois, ao buscar resolver um problema, o aluno passa por um momento de reflexão. "Terminado este momento de reflexão que Vergnaud (1982) denominou de cálculo relacional, o aluno passa para, segundo ele, para o cálculo numérico. É neste momento em que ele se depara com os seus conhecimentos operacionais matemáticos" (QUEIROZ; LINS, 2011, p.81). De acordo com Pessoa e Filho (2006), Vergnaud (1991) defende que:

\footnotetext{
a ampliação da perspectiva conceitual de uma criança exige a competência para a realização do cálculo relacional que a capacita para a escolha da operação adequada ao que o problema propõe e para a realização do cálculo numérico correspondente. A diversificação e a contextualização de situações colocadas para o aluno são importantes no sentido de ajudá-lo a operar e relacionar situações e aprendizagens de diferentes maneiras (PESSOA; FILHO, 2006, p. 4).
}

Neste sentido, o cálculo relacional diz respeito ao momento de decisão em que o aluno escolhe a operação apropriada para resolvê-lo, e o cálculo numérico, à realização propriamente dita deste cálculo (QUEIROZ; LINS, 2011). O cálculo relacional está voltado para os procedimentos anteriores ao cálculo numérico. Onde o aluno busca a melhor opção para a resolução do problema a ele apresentado, a melhor operação. E, o cálculo numérico, diz 
respeito aos conhecimentos operacionais matemáticos, mais precisamente, relacionado à execução de algoritmos.

Com base na perspectiva vergnaudiana sobre o cálculo relacional e o cálculo numérico e nas considerações apresentadas sobre a Teoria dos Campos Conceituais e o campo conceitual multiplicativo apresentamos a seguir o delineamento metodológico do presente estudo.

\section{Metodologia}

A pesquisa foi realizada em uma escola pública na cidade do Recife- PE. Nesta escola havia cinco turmas do $6^{\circ}$ ano do ensino fundamental, divididas em três turmas pelo horário da manhã e duas turmas pelo horário da tarde, onde cada turno tem um professor diferente. A pesquisa foi realizada em todas as turmas com os alunos que se encontravam presentes no dia da aplicação da sondagem.

Foi proposto que os alunos respondessem uma atividade de sondagem contendo cinco situações-problemas do campo conceitual multiplicativo.

Quadro 1: Tipos de situações-problemas aplicadas na sondagem

\begin{tabular}{|c|c|c|l|}
\hline Relações & Eixos & Classes & \multicolumn{1}{c|}{ Situações-problemas } \\
\hline \multirow{2}{*}{ Quaternária } & $\begin{array}{c}\text { Proporção } \\
\text { simples }\end{array}$ & Partição & $\begin{array}{l}\text { Guilherme comprou por 35 reais 5 carrinhos. Qual } \\
\text { o preço de um carrinho? }\end{array}$ \\
\cline { 3 - 4 } & Quotição & $\begin{array}{l}\text { Bruna tem 340 reais para comprar bonecas a 4 reais } \\
\text { cada uma. Quantas bonecas ela poderá comprar? }\end{array}$ \\
\hline \multirow{4}{*}{ Terciária } & $\begin{array}{c}\text { Comparação } \\
\text { Multiplicativa }\end{array}$ & $\begin{array}{l}\text { Referente } \\
\text { desconhecido }\end{array}$ & $\begin{array}{l}\text { Uma cozinheira ganhou 180 reais por um kit festa. } \\
\text { Ela ganhou 4 vezes mais do que sua ajudante } \\
\text { recebeu. Quantos reais a ajudante da cozinheira } \\
\text { recebeu? }\end{array}$ \\
\cline { 2 - 4 } & $\begin{array}{c}\text { Relação } \\
\text { desconhecida }\end{array}$ & $\begin{array}{l}\text { Uma costureira recebeu 125 reais por uma roupa } \\
\text { que fez e sua ajudante, 25 reais. Quem recebeu } \\
\text { mais dinheiro e quantas vezes mais? }\end{array}$ \\
\cline { 2 - 4 } & $\begin{array}{c}\text { Produto de } \\
\text { medidas }\end{array}$ & Combinatória & $\begin{array}{l}\text { Trocando os shorts e as blusas, Lila pode fazer 24 } \\
\text { looks. Lila tem 4 shorts, quantas blusas ela tem? }\end{array}$ \\
\hline
\end{tabular}

Fonte: adaptado Magina; Merlini e Santana (2013).

Na aplicação da atividade, os alunos tiveram duas aulas para respondê-la. Dadas as seguintes orientações: os alunos foram solicitados a responder as situações-problemas individualmente; sem ajuda do professor da turma e sem intervenção do pesquisador. Destacamos que não foi indicada a operação que deveria ser usada par resolver as situaçõesproblemas. 
Quanto à análise de dados, ela foi organizada em 4 etapas. $\mathrm{Na} 1^{\mathrm{a}}$ etapa, realizamos a correção das situações-problemas propostas aos alunos. Na $2^{\mathrm{a}}$ etapa, mapeamos as resoluções com acerto e com erro no cálculo relacional e/ou no cálculo numérico. Foi considerado acerto no cálculo relacional quando os alunos optaram por uma operação que os levassem a chegar à resposta correta. Neste caso, foram consideradas todas as operações (divisão, multiplicação, adição e subtração). Para o erro no cálculo relacional, levamos em conta as operações que não fariam os alunos chegar à resposta correta, independente de terem acerto no cálculo numérico. Quanto ao acerto no cálculo numérico, consideramos os procedimentos operatórios corretos dos algoritmos e para os erros, as falhas destes procedimentos.

$\mathrm{Na} 3^{\mathrm{a}}$ etapa, foi feito o levantamento das situações-problemas que apresentaram menor e maior número de dificuldades dos alunos para serem resolvidas.

Por fim, na $4^{\text {a }}$ etapa, procedemos a análise do tratamento das estratégias utilizadas pelos alunos para resolverem as situações-problemas, observando os tipos de operações utilizadas e os acertos e os erros para cada uma delas, bem como aquelas que foram deixadas em branco. Exposta a organização metodológica do presente estudo, apresentamos a seguir os resultados.

\section{Resultados}

No presente estudo, os alunos do $6^{\circ}$ ano do EF obtiveram o maior número de acertos (Figura 2) na situação-problema 1 de relação quaternária, do eixo proporção simples (partição). As situações-problema 3 e 5 de relação terciária, respectivamente do eixo comparação multiplicativa (procura do referente) e do eixo produto de medidas (combinatória) foram aquelas que obtiveram o maior número de erros.

Figura 2: Panorama da resolução das situações-problemas

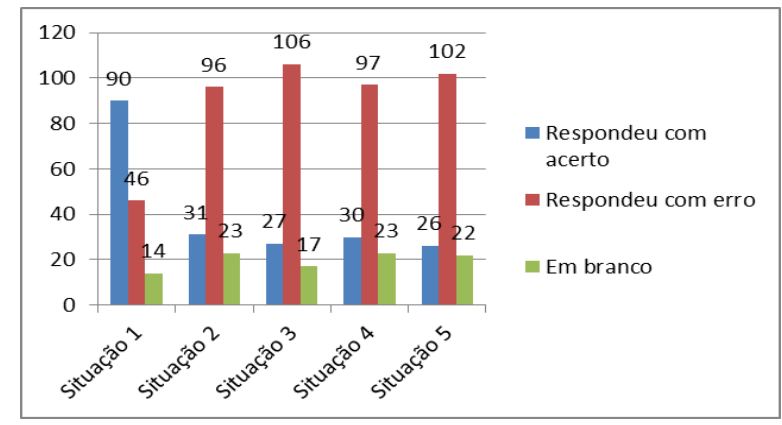

Fonte: autoria própria 
Expomos no Quadro 2, os acertos e erros nos cálculos dos alunos para a situaçãoproblema 1, associada à ideia de partição: Guilherme comprou por 35 reais 5 carrinhos. Qual o preço de um carrinho?

Quadro 2: Resultados da situação-problema 1

\begin{tabular}{|c|c|c|c|}
\hline Operações & Categorias de cálculo & \multicolumn{2}{|c|}{$\mathrm{N}^{\mathrm{o}}$ de alunos } \\
\hline \multirow{2}{*}{ Divisão } & Acertos no cálculo relacional e cálculo numérico & 67 & \multirow{2}{*}{80} \\
\hline & Acerto no cálculo relacional e erro no cálculo numérico & 13 & \\
\hline \multirow{3}{*}{ Multiplicação } & Acerto no cálculo relacional e acerto no cálculo numérico & 15 & \multirow{3}{*}{30} \\
\hline & Erro no cálculo relacional e acerto no cálculo numérico & 7 & \\
\hline & Erro no cálculo relacional e erro no cálculo numérico & 8 & \\
\hline \multirow{3}{*}{ Adição } & Acertos no cálculo relacional e cálculo numérico & 8 & \multirow{3}{*}{18} \\
\hline & Erro no cálculo relacional e acerto no cálculo numérico & 5 & \\
\hline & Erro no cálculo relacional e erro no cálculo numérico & 5 & \\
\hline \multirow[t]{3}{*}{ Subtração } & Erro no cálculo relacional e acerto no cálculo numérico & 6 & \multirow[t]{2}{*}{8} \\
\hline & Erro no cálculo relacional e erro no cálculo numérico & 2 & \\
\hline & Em branco & 14 & 14 \\
\hline \multicolumn{3}{|c|}{ Total } & 150 \\
\hline
\end{tabular}

Fonte: autoria própria.

Na situação-problema 1,80 alunos utilizaram a operação de divisão para resolvê-la (Figuras 3 a 6). Dentre estes, 67 alunos responderam esta situação com acerto no cálculo relacional e no cálculo numérico. Na resolução da divisão (35: 5) ocorreu vários tipos de representações simbólicas, por exemplo: horizontal (Figura 3), processo longo (Figura 6) entre outros.

Figura 3: S1- Divisão I

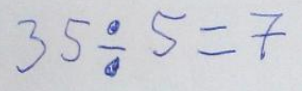

Fonte: Aluno A6C18

Figura 5: S1- Divisão III

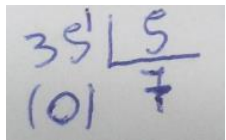

Fonte: Aluno A6A13
Figura 4: S1- Divisão II

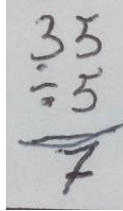

Fonte: Aluno A6E31

Figura 6: S1- Divisão IV

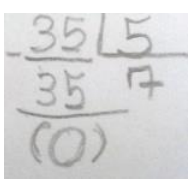

Fonte: Aluno A6E29

Ainda sobre a situação-problema 1, ocorreram casos com o uso da divisão (35:5), onde alguns alunos não conseguiram efetuar o cálculo numérico corretamente (Figura 7). Neste caso, temos indícios sobre as dificuldades dos alunos em contagem. 
Figura 7: S1- Divisão V

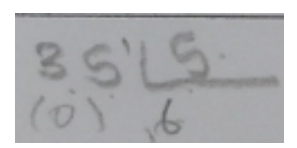

Fonte: Aluno A6E15

A segunda operação mais utilizada na resolução da situação-problema 1 (Quadro 2) foi a multiplicação (Figura 8 a 10). Em um total de 30 alunos, 15 deles acertaram o uso da multiplicação para resolver a situação-problema, tanto no cálculo relacional, quanto no cálculo numérico.

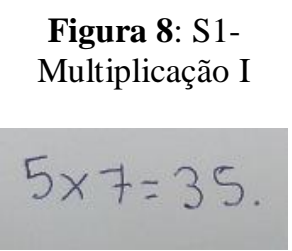

Fonte: Aluno A6D22
Figura 9: S1Multiplicação II

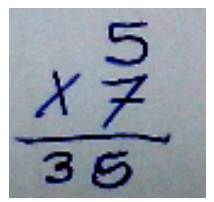

Fonte: Aluno A6B12
Figura 10: S1- Multiplicação III

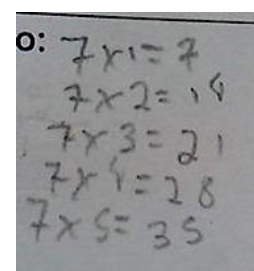

Fonte: A6A4

Na Figura 8 e 9, os alunos praticamente escreveram na forma de sentença matemática ou do algoritmo da multiplicação a operação realizada mentalmente $(5 \times 7=35)$. No caso da Figura 10, o aluno usou como estratégia de resolução o uso da tabuada, na medida em que foi multiplicando $(7 \times 1=7 ; 7 \times 2=14 \ldots)$ até chegar ao valor desejado $(7 \times 5=35)$. Houve 7 casos em que a situação-problema 1 foi resolvida com erro no cálculo relacional e acerto no cálculo numérico, como pode ser observado na Figura 11. Enquanto ocorreu 8 casos com erro em ambos os cálculos, tanto relacional como numérico, mostrado na Figura 12.

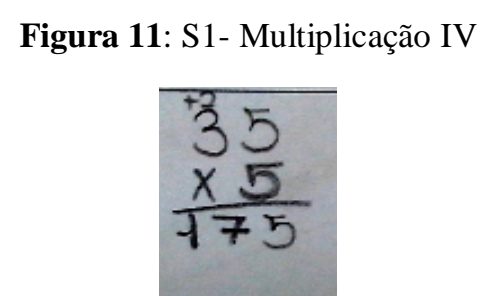

Fonte: Aluno A6B17
Figura 12: S1- Multiplicação V

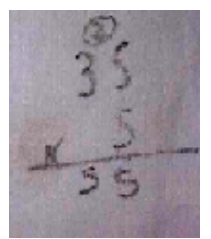

Fonte: Aluno A6C9

A terceira operação mais escolhida pelos alunos para resolver a situação-problema 1 foi a adição. Em um total de 18 alunos, apenas 8 deles acertaram no cálculo relacional e 
numérico (Figura 13). Dentre estes, houve também alunos que erraram no cálculo relacional e acertaram no numérico (Figura 14).

Figura 13: S1- Adição I

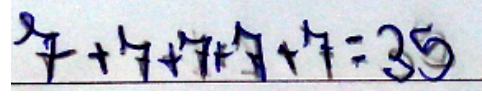

Fonte: Aluno A6D11
Figura 14: S1- Adição II

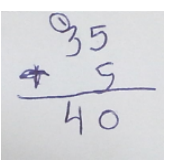

Fonte: Aluno A6C21

Já a operação menos usada pelos alunos na resolução da situação-problema 1 foi a subtração $(35-5=30)$. Apenas 8 deles a escolheram e aconteceu que não houve acerto no cálculo relacional e a maioria acertou no cálculo numérico.

No Quadro 3, podemos ver os resultados na resolução da situação-problema 2, também de proporção simples, onde se fazia necessário a procura da quantidade de unidades; ou seja, a divisão por quota, associada à ideia de "quantas vezes uma quantidade cabe em outra": Bruna tem 340 reais para comprar Barbie a 4 reais cada uma. Quantas Bonecas ela poderá comprar?

Quadro 3: Resultados da situação-problema 2

\begin{tabular}{|c|c|c|c|}
\hline Operações & Categorias de cálculo & \multicolumn{2}{|c|}{$\mathrm{N}^{\mathrm{o}}$ de alunos } \\
\hline \multirow{2}{*}{ Divisão } & Acertos no cálculo relacional e cálculo numérico & 30 & \multirow{2}{*}{52} \\
\hline & Acerto no cálculo relacional e erro no cálculo numérico & 22 & \\
\hline \multirow{3}{*}{ Multiplicação } & Acerto no cálculo relacional e acerto no cálculo numérico & 1 & \multirow{3}{*}{40} \\
\hline & Erro no cálculo relacional e acerto no cálculo numérico & 18 & \\
\hline & Erro no cálculo relacional e erro no cálculo numérico & 21 & \\
\hline \multirow[t]{2}{*}{ Adição } & Erro no cálculo relacional e acerto no cálculo numérico & 16 & \multirow{2}{*}{26} \\
\hline & Erro no cálculo relacional e erro no cálculo numérico & 10 & \\
\hline \multirow[t]{3}{*}{ Subtração } & Erro no cálculo relacional e acerto no cálculo numérico & 1 & \multirow[t]{2}{*}{9} \\
\hline & Erro no cálculo relacional e erro no cálculo numérico & 8 & \\
\hline & Em branco & 23 & 23 \\
\hline \multicolumn{3}{|c|}{ Total } & 150 \\
\hline
\end{tabular}

Fonte: autoria própria.

$\mathrm{Na}$ resolução da situação-problema 2, a operação mais usada pelos alunos foi a divisão, com 52 alunos no total e destes 30 acertaram tanto no cálculo relacional como no cálculo numérico ( Figura 15). Contudo, 22 alunos acertaram no cálculo relacional e erraram o cálculo numérico (Figura 17).

\begin{tabular}{|c|c|}
\hline Figura 15: S2- Divisão I & Figura 16: S2- Divisão II \\
\hline $340 \frac{4}{85}$ & $\frac{340 \frac{4}{850}}{20}$ \\
$20 / 0)$ & Fonte: Aluno A6B18 \\
\hline
\end{tabular}


Vale ressaltar que no caso do aluno A6B18 (Figura 16) houve um evidente erro relativo ao zero no resto, quando o aluno retomou a divisão $(0: 4=0)$ e não se apercebe que o resultado do quociente não poderia ser maior que o do dividendo.

A segunda operação mais escolhida pelos alunos para a resolução da situaçãoproblema 2 foi a multiplicação (40 alunos). Porém, apenas 1 aluno acertou (Figura 17), tanto no cálculo relacional quanto no cálculo numérico.

Figura 17: S2- Multiplicação I

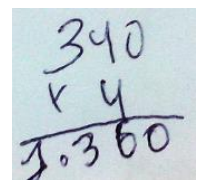

Fonte: Aluno A6E32
Figura 18: S2- Multiplicação II

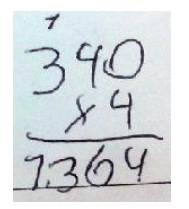

Fonte: Aluno A6C24

Na Figura 18, temos um exemplo de um aluno que acertou no cálculo relacional e errou no cálculo numérico. Neste caso, o aluno multiplicou o valor de $4 \times 0=4$. Isto foi bem frequente entre os demais alunos.

Os alunos que usaram a adição na resolução da situação-problema 2, errou no cálculo relacional e a maioria acertou no cálculo numérico. Foi possível identificar dificuldades em efetuar a soma $(340+4)$. Na Figura 19, temos um exemplo, onde o aluno ao adicionar $340+$ 4, apresentou a resposta 340. Na Figura 20, supomos que o aluno A6A31 efetuou a soma de uma unidade com uma dezena $(4+4=8)$ e somou também a unidade com uma centena $(4+3$ $=7)$.

Figura 19: S2- Adição I

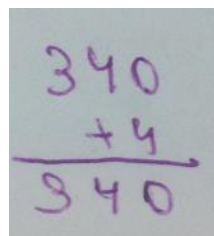

Fonte: Aluno A6C30
Figura 20: S2- Adição II

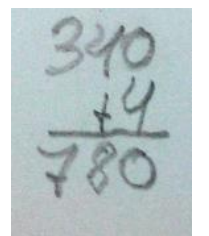

Fonte: Aluno A6A31

A operação na qual os alunos menos recorreu para responder a situação-problema 2 foi a subtração (apenas 9 alunos). Dentre eles, apenas 1 aluno acertou no cálculo numérico (Figura 21 e 22).Todos erraram no cálculo relacional. 
Figura 21: S2- Subtração I

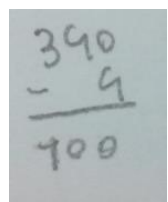

Fonte: Aluno A6D30
Figura 22: S2- Subtração II

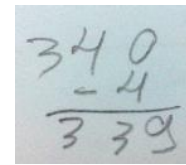

Fonte: Aluno A6B3

O erro apresentado pelo aluno A6D30 (Figura 21) se configurou em subtrair " $0-4=$ 0". Além disto, ter subtraído " 4 dezenas de 4 unidades" e depois " $4-3=1$ " (sendo 3 centenas e 4 unidades); obtendo o resultado final igual a 100, quando deveria ser 336. A Figura 22 demonstra um exemplo de difícil compreensão da estratégia utilizada pelos alunos no cálculo numérico da subtração.

No caso da situação-problema 3 ( Quadro 3) do eixo de situações de comparação multiplicativa, onde era necessário calcular quanto ganhou a ajudante (referente): Uma cozinheira ganhou 180 reais por um kit festa. Ela ganhou 4 vezes mais do que sua ajudante recebeu. Quantos reais a ajudante da cozinheira recebeu? - os resultados foram os seguintes:

Quadro 3: Resultados da situação- problema 3

\begin{tabular}{|c|c|c|c|}
\hline Operações & Categorias de cálculo & $\mathrm{N}^{\mathrm{o}}$ de aluı & \\
\hline \multirow{3}{*}{ Multiplicação } & Acerto no cálculo relacional e acerto no cálculo numérico & 7 & \multirow{3}{*}{51} \\
\hline & Erro no cálculo relacional e acerto no cálculo numérico & 24 & \\
\hline & Erro no cálculo relacional e erro no cálculo numérico & 20 & \\
\hline \multirow{2}{*}{ Divisão } & Acerto no cálculo relacional e acerto no cálculo numérico & 20 & \multirow{2}{*}{34} \\
\hline & Acerto no cálculo relacional e erro no cálculo numérico & 14 & \\
\hline \multirow[t]{2}{*}{ Subtração } & Erro no cálculo relacional e acerto no cálculo numérico & 16 & \multirow{2}{*}{29} \\
\hline & Erro no cálculo relacional e erro no cálculo numérico & 13 & \\
\hline \multirow{2}{*}{ Adição } & Erro no cálculo relacional e acerto no cálculo numérico & 9 & \multirow{2}{*}{19} \\
\hline & Erro no cálculo relacional e erro no cálculo numérico & 10 & \\
\hline \multicolumn{3}{|c|}{ Em branco } & 17 \\
\hline & & Total & 150 \\
\hline
\end{tabular}

Fonte: autoria própria.

A maioria dos alunos buscou resolver a situação-problema 3 (Quadro 3), utilizando a operação de multiplicação. Neste caso, um número reduzido de alunos acertou no cálculo relacional e numérico (7 em 51 alunos). Ou seja, multiplicou 45 x 4 ou vice-versa, encontrando o resultado 180. Dentre os alunos que apenas acertou o cálculo numérico, a maioria destes, efetuou 4 x $180=720$. De outro modo, foi recorrente, as dificuldades em relação ao zero na multiplicação (Figura 23 e 24). 
Figura 23: S3 - Multiplicação I

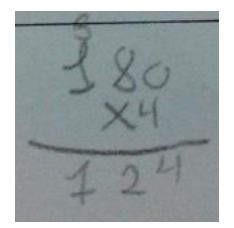

Fonte: Aluno A6B4
Figura 24: S3 - Multiplicação II

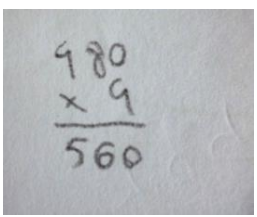

Fonte: Aluno A6A2

Quanto a segunda operação mais empregada para resolver a situação-problema 3 - a divisão - identificamos que dentre 34 alunos, 20 deles acertou no cálculo relacional e numérico. Isto é, dividiram 180 por 4, obtendo o resultado 45. Contudo, no cálculo numérico, diversas ordens de dificuldades dos alunos foram identificadas. Por exemplo: contagem (Figura 25) e inversão do resultado entre quociente e resto (Figura 26).

Figura 25: S3- Divisão I

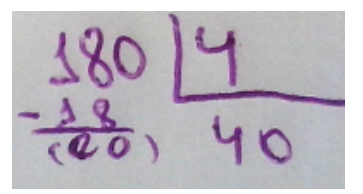

Fonte: Aluno A6B8
Figura 26: S3- Divisão II

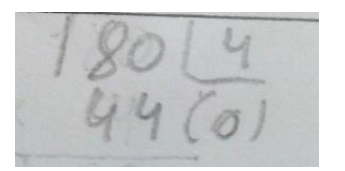

Fonte: Aluno A6B32

Quanto ao uso da subtração, a maior parte dos alunos que chegou a acertar o cálculo numérico utilizou o procedimento 180 - 6, encontrando assim o resultado 176. Contudo, dentre 29 alunos que utilizou esta operação, 13 erraram neste tipo de cálculo.

Neste caso, foram apresentados os erros, de modo mais frequente, aqueles cujo resultado da subtração 180 - 4 foi igual a 140 ou 144. Temos assim, seja um erro em virtude da supremacia do zero; seja, pela ideia de zero neutro. Onde, deparando-se com o zero, automaticamente, os alunos reproduzem o zero no resto ou a presença do zero é ignorada, sendo repetidos os valores do subtraendo (QUEIROZ; LINS, 2011).

Por fim, na resolução da situação-problema 3, em menor medida, os alunos utilizaram a operação de adição. $\mathrm{O}$ erro no cálculo relacional e acerto no cálculo numérico ocorreram em torno de dois tipos de resultados (figuras 27 e 28): 184 (A6B22) e 720 (A6C6).

Figura 27: S3 -Adição I

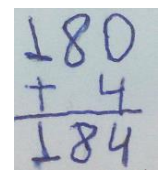

Fonte: Aluno A6B22
Figura 28: S3 -Adição II

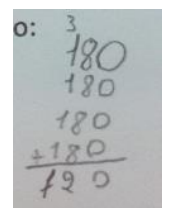

Fonte: Aluno A6C6 
Deste modo, podemos identificar na Figura 28, a referência à soma de parcelas repetidas, o que nos remete a um resultado que poderia ser encontrado pela multiplicação. Quanto aos erros no cálculo numérico, além das dificuldades dos alunos em operar com o zero, identificamos dificuldades sobre as regras de valor posicional das centenas, dezenas e unidades. Visto que, a exemplo do aluno A6A29 (Figura 29), ele somou as centenas +4 unidades, obtendo assim, o resultado final 624. E, o aluno A6E7 (Figura 30), somou 8 dezenas +4 unidades, obtendo o resultado final 220 .

Figura 29: S3 - Adição III

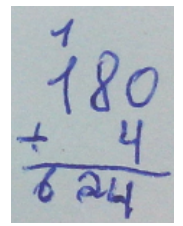

Fonte: Aluno A6A29
Figura 30: S3 -Adição IV

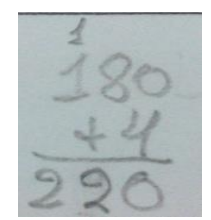

Fonte: Aluno A6E7

Em relação a situação-problema 4: uma costureira recebeu 125 reais por uma roupa que fez e sua ajudante, 25 reais. Quem recebeu mais dinheiro e quantas vezes mais? Onde os alunos deveriam indicar o valor da relação. Podemos ver no quadro a seguir, uma síntese de seus resultados:

Quadro 4: Resultados da situação-problema 4

\begin{tabular}{|c|c|c|c|}
\hline Operações & Categorias de cálculo & Quantidade de & unos \\
\hline \multirow[t]{3}{*}{ Multiplicação } & Acerto no cálculo relacional e acerto no cálculo numérico & 16 & \multirow{3}{*}{42} \\
\hline & Erro no cálculo relacional e acerto no cálculo numérico & 4 & \\
\hline & Erro no cálculo relacional e erro no cálculo numérico & 22 & \\
\hline \multirow[t]{3}{*}{ Adição } & Acerto no cálculo relacional e acerto no cálculo numérico & 7 & \multirow{3}{*}{36} \\
\hline & Erro no cálculo relacional e acerto no cálculo numérico & 23 & \\
\hline & Erro no cálculo relacional e erro no cálculo numérico & 6 & \\
\hline Subtração & Erro no cálculo relacional e acerto no cálculo numérico & 34 & 34 \\
\hline \multirow[t]{2}{*}{ Divisão } & Acerto no cálculo relacional e acerto no cálculo numérico & 7 & \multirow[t]{2}{*}{15} \\
\hline & Acerto no cálculo relacional e erro no cálculo numérico & 8 & \\
\hline & & Em branco & 23 \\
\hline & & Total & 150 \\
\hline
\end{tabular}

Fonte: autoria própria.

De modo semelhante ao que ocorreu na situação-problema 3, a maioria dos alunos buscou resolver a situação-problema 4, utilizando a operação de multiplicação (Quadro 4). Isto é, calcularam 5 x 25, encontrando o resultado 125. Desta forma, determinando o valor da relação igual a 5. Os erros de cálculo numérico quanto à multiplicação revelaram, sobretudo, a dificuldade dos alunos em operar com um termo de dois algarismos: 125 x 25 (figuras 31 e 32). Devido à localização do produto das dezenas ser posto no local das unidades. 
Figura 31: S4 - Multiplicação I

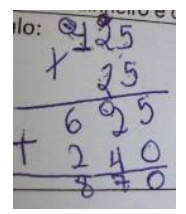

Fonte: Aluno A6B26
Figura 32: S4 - Multiplicação II

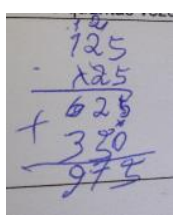

Fonte: Aluno A6A28

Em segundo lugar, a operação mais utilizada pelos alunos para resolver o situaçãoproblema 4 foi a adição, basicamente, pelo procedimento $125+25=150$. Desta forma, configurando um maior número de erro no cálculo relacional e acerto no cálculo numérico. No entanto, em menor medida, outros alunos (Quadro 4) chegaram a encontrar o valor esperado da relação igual a 5, adicionando sucessivas parcelas de 25 até chegar ao valor 125 (figuras 33 e 34 ).

Figura 33: S4 - Adição I

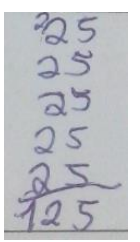

Figura 34: S4 - Adição II

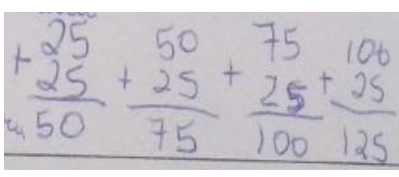

Fonte: Aluno A6C22

Fonte: Aluno A6A18

É provável que a presença da expressão vezes mais no enunciado da situação-problema 4, tenha influenciado uma ênfase dos alunos em utilizar a adição para resolvê-la. Fato este, menos percebido na resolução da situação-problema 3 .

Em terceiro lugar, a operação mais utilizada para resolver situação-problema 4 foi a subtração, sem maiores dificuldades quanto ao cálculo numérico. Visto que, notadamente os alunos realizaram o cálculo 125 -25, obtendo o resultado 100.

$\mathrm{Na}$ situação-problema 4, em menor medida, os alunos utilizaram a operação de divisão. Dentre aqueles que utilizaram esta operação, com acertos no cálculo relacional e numérico, foi realizada a operação 125: 25, encontrando o valor 5. Dentre aqueles que erraram no cálculo numérico desta, selecionamos, por exemplo, casos em que os alunos demonstraram dificuldade sobre os procedimentos aritméticos necessários para resolver a divisão em questão, apresentando resultados exatos, como provenientes da multiplicação $21 \mathrm{x}$ 25 (Figura 35) ou 43 x 25 (Figura 36). 
Figura 35: S4 - Divisão I

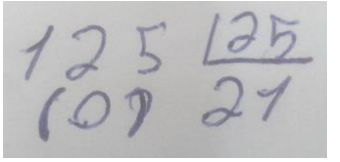

Fonte: Aluno A6D4
Figura 36: S4 - Divisão II

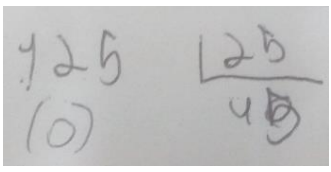

Fonte: Aluno A6E28

$\mathrm{Na}$ resolução da situação-problema 5 , do eixo produto de medidas, da classe de combinatória: "Trocando os seus shorts e blusas, Lila pode fazer 24 looks. Lila tem 4 shorts, quantas blusas ela tem?”; constatamos um número significativo de alunos que utilizou a operação de adição ou de subtração.

Quadro 5: Resultados da resolução da situação-problema 5

\begin{tabular}{|c|l|c|c|}
\hline Operações & \multicolumn{1}{|c|}{ Categorias de cálculo } & \multicolumn{2}{|c|}{$N^{\text {o }}$ de alunos } \\
\hline \multirow{2}{*}{ Adição } & Acerto no cálculo relacional e acerto no cálculo numérico & 2 & \multirow{2}{*}{46} \\
\cline { 2 - 3 } & Erro no cálculo relacional e acerto no cálculo numérico & 44 & \\
\hline \multirow{2}{*}{ Subtração } & Erro no cálculo relacional e acerto no cálculo numérico & 39 & 39 \\
\hline \multirow{2}{*}{ Divisão } & Acerto no cálculo relacional e acerto no cálculo numérico & 22 & \multirow{2}{*}{24} \\
\cline { 2 - 3 } & Acerto no cálculo relacional e erro no cálculo numérico & 2 & \\
\hline \multirow{2}{*}{ Multiplicação } & Acerto no cálculo relacional e acerto no cálculo numérico & 2 & \multirow{2}{*}{19} \\
\cline { 2 - 3 } & Erro no cálculo relacional e acerto no cálculo numérico & 9 & \\
\cline { 2 - 3 } & Erro no cálculo relacional e erro no cálculo numérico & 8 & \\
\hline & Em branco & 22 & 22 \\
\hline & & Total & 150 \\
\hline
\end{tabular}

Fonte: autoria própria.

Notamos no Quadro 5 que a maioria dos alunos buscou resolver a situação-problema de combinatória usando a operação de adição (46 alunos). Vale salientar que estes alunos efetuaram a soma $24+4$, na ordem em que se apresentaram na situação-problema, encontrando o resultado 28. Quanto aos alunos que utilizaram a operação de adição e acertaram no cálculo relacional e numérico, tivemos apenas a ocorrência de dois casos (Quadro 5). Vejamos o exemplo a seguir.

Figura 37: S5 - Adição I

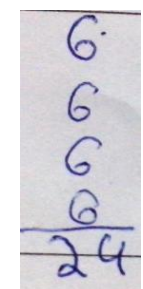

Fonte: Aluno A6E13 
No caso do procedimento exposto na Figura 37, os alunos indicam haver utilizado o raciocínio multiplicativo, ou seja, buscaram repetir a quantidade 6 quatro vezes a fim de obter o resultado 24 .

De outro modo, podemos identificar que a segunda operação mais utilizada para resolver a situação-problema de combinatória foi a subtração, visto que 39 alunos a escolheram, errando no cálculo relacional e acertando no cálculo numérico ( Quadro 5). Onde o principal procedimento utilizado foi 24 - 4, obtendo assim o resultado 20. Estes cálculos sugerem que ao subtrair a quantidade 4 (shorts) do total de combinações, o valor restante seria o da quantidade de blusas.

Ao analisarmos a terceira operação mais utilizada para resolver a situação-problema 5 - a divisão; identificamos que dentre 24 alunos que a utilizaram, foi quase unânime, os acertos no cálculo relacional e numérico. Isto é 22 alunos dividiram 24 por 4 , obtendo o resultado 6 , embora com diferentes tipos de representações simbólicas.

Figura 38: S5 - Divisão I

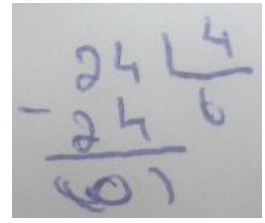

Fonte: Aluno A6B18
Figura 39: S5- Divisão II

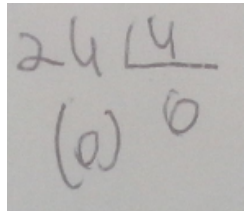

Fonte: Aluno A6E20
Figura 40: S5 - Divisão III

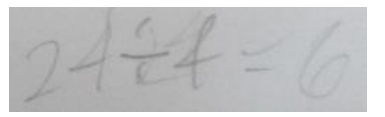

Fonte: Aluno A6D23

No exemplo da Figura 38 e da Figura 39, os alunos optaram por utilizar o processo "longo" ou "curto" da divisão. Enquanto, no exemplo da Figura 40, ao que parece, os alunos já sabiam a resposta e tiveram em mente apresentar a formalização da representação da sentença $24: 4=6$. É importante salientar que também ocorreram erros no cálculo numérico quanto a divisão (Figura 41 e Figura 42). Apenas em 2 casos (Quadro 5) os alunos demonstraram ter conhecimento sobre a operação adequada à resolução da situação-problema e não conseguiram acertar no cálculo numérico.

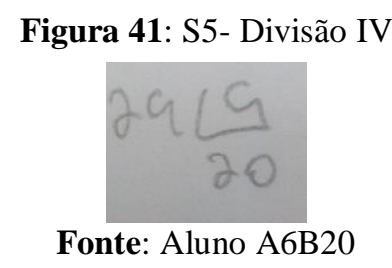

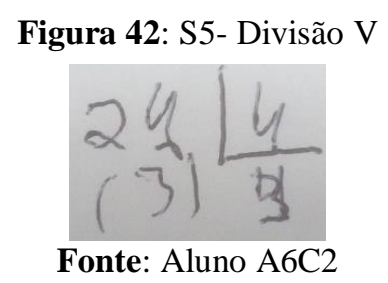

Por fim, a operação menos utilizada pelos alunos para resolver a situação-problema 5 , foi a multiplicação (Quadro 5). A maior parte dos alunos (Figura 43) que chegou a utilizar a 
multiplicação errou no cálculo relacional e acertou no cálculo numérico, utilizando o procedimento 24 x 4, encontrando assim o resultado 96. Destacamos que apenas dois alunos chegaram à resposta correta (Figura 44).

Figura 43: S5- Multiplicação I

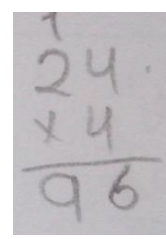

Fonte: Aluno A6E12
Figura 44: S5- Multiplicação II

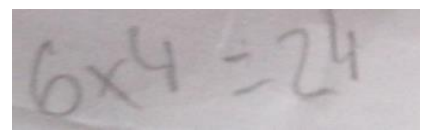

Fonte: Aluno A6E31

Consideramos que o panorama dos procedimentos utilizados pelos alunos no que concerne a escolha das operações (adição, subtração multiplicação e/ou divisão) para resolver a situações-problema aqui tratadas, reafirmam a importância de que as situações, não podem ser analisadas com a ajuda de apenas um conceito. Isso significa que uma situação, por mais simples que seja, envolve mais de um conceito.

\section{Considerações finais}

O objetivo deste trabalho foi pautado em reconhecer as dificuldades dos alunos do $6^{\circ}$ ano do Ensino Fundamental na resolução de situações-problemas do campo conceitual multiplicativo, demonstradas nos seus procedimentos de cálculo relacional e numérico. Assim, quando comparamos os resultados de cada tipo de situação-problema, em todas elas, houve maior número de acertos no cálculo numérico que no relacional.

Constatamos que as situações-problema 3 e 4 referentes à comparação multiplicativa e a situação-problema 5 de produto de medidas foram aquelas que apresentaram maior dificuldade no cálculo relacional. Isto indica uma atenção especial às situações-problemas de relação ternária, tendo em vista que os alunos parecem mais familiarizados com a resolução de situações-problemas de relação quaternária; sobretudo envolvendo a ideia de partição (Figura 2).

Tais resultados reafirmam a importância de serem trabalhados diversos tipos de situações do campo conceitual multiplicativo, a fim de serem superadas as dificuldades dos alunos, dentre outras, no que diz respeito ao cálculo relacional.

\section{Referências}

BRASIL. Ministério da Educação e do Desporto. Parâmetros Curriculares Nacionais. Matemática. Brasília: MEC/SEF, 1997. 
FRANCHI, Anna. Considerações sobre a teoria dos campos conceituais. In: MACHADO, Silva Dias Alcântara (Org.). Educação matemática: uma (nova) introdução. 3 ed. São Paulo: EDUC, 1999.

MAGINA, S.; MERLINI, V.L.; SANTANA, E. Situações-problema das estruturas multiplicativas sob a ótica do professor que ensina matemática. In: CIBEM, VII, 2013. Montevideo-Uruguay. Anais... Montevideo, 2013, p. 5980-5987.

MOREIRA, M. A. A teoria dos campos conceituais de Vergnaud, o ensino de ciências e a pesquisa nesta área. Investigações em Ensino de Ciências, v.7(1), p. 7-29, 2002.

PERNAMBUCO. Secretaria de Educação. Parâmetros para a educação básica do Estado de Pernambuco. Parâmetros Curriculares de Matemática de Pernambuco para o Ensino Fundamental e Médio. Recife: Secretaria de Educação, 2012.

PESSOA, C; FILHO, M. Estruturas multiplicativas: como os alunos compreendem os diferentes tipos de problemas. In: SIPEMAT, 2006, Recife. Anais.... Recife. UFPE, 2006, p.1-11.

QUEIROZ, S.; LINS, M. A aprendizagem de matemática por alunos adolescentes na modalidade educação de Jovens e adultos: analisando as dificuldades na resolução de problemas de estrutura aditiva. Bolema, Rio Claro (SP), v. 24, n. 38, p. 75- 96, abr. 2011.

VERGNAUD, G. La théorie des champs conceptuels. Recherches en Didactique des Mathématiques.Grenoble, v. 10, n. 23, p. 133-170, 1990.

VERGNAUD, G. El niño, las matemáticas y la realidad: problemas de la enseñanza de las matemáticas en la escuela primaria. México: Trillas, 1991.

VERGNAUD, G. Teoria dos campos conceituais. In: SEMINÁRIO INTERNACIONAL DE EDUCAÇÃO MATEMÁTICA, 1. 1993, Rio de Janeiro. Anais... Rio de Janeiro, 1993, p. 1-26.

Recebido em 18/03/2017 - Aceito em 31/10/2017 